\title{
THE PATTERN OF EVOLUTIONARY CHANGE IN BACTERIA
}

\author{
R. W. HEDGES \\ Bacteriology Department, Royal Postgraduate Medical School, \\ DuCane Road, London, W.12
}

Received 22.iii.71

\section{INTRODUGTION}

DAYHOFF (1969) analysed evolutionary changes in amino-acid sequences of proteins. For several, e.g. the haemoglobins and cytochrome c, data were sufficient for " phylogenetic trees" to be constructed. Each " tree " relates to a single group of homologous proteins. It is satisfying that they conform with classical ideas on the pattern of evolution. In particular, the "trees" for the evolution of various proteins did not show incongruities. Thus, it seems that the proteins of a particular species have evolved continuously together.

This conclusion is based upon evidence from eukaryotes. Recently the analysis has been extended to prokaryotic organisms (Mandel, 1969; McLaughlin and Dayhoff, 1970). This paper questions whether data derived from such organisms can be used to construct "phylogenetic trees" to interpret the evolutionary history of the organisms in the same way as data from eukaryotes.

There are many differences between the genetic organisation of prokaryotes and eukaryotes. The bacterial chromosome and plasmids normally exist as circular DNA molecules, genetic transfer in bacteria rarely, if ever, involves transfer of complete genomes and the genetic information of the bacterial chromosome is organised so that in many cases a gene is closely linked to related genes (e.g. Demeree, 1964).

The thesis argued is that genomes of bacteria evolved in a patchwork fashion and that even if one knew the complete evolutionary history of the amino-acid sequence of a particular protein one could deduce little about the evolutionary history of the bacteria.

A simple case is presented by the antibiotic resistance plasmids ( $R$ factors) of Gram-negative bacteria. These plasmids are aggregations of genes related functionally but not metabolically. One of the $R$ factor-borne markers is chloramphenicol resistance. This is due to chloramphenicol acetyl-transferase (Shaw, 1967). The origin of the genes constituting $R$ factors is a matter for speculation. Datta (1965) suggested that the chloramphenicol resistance gene may have been derived from Klebsiella.

$R$ factors may be transferred not only between the various genera of the family Enterobacteriaceae (Nakaya, Nakamura and Murata, 1960) but also to Pasteurella (Martin and Jacob, 1962), Proteus and Serratia (Rownd, Nakaya and Nakamura, 1966) and even to certain bacteria classified outside the order Eubacteriales, for example Vibrio (Baron and Falkow, 1961) and Pseudomonas (Fullbrook, Elson and Slocombe, 1970; Sykes and Richmond, 1970).

Such exchanges complicate analysis of the evolutionary history and further complications arise. In the case described, the genes remain part of a plasmid, replicating independently of the chromosome constituting a dispensible part of the bacterial genome (Jacob, Schaeffer and Wollman, $1960)$. The $R$ factor may be able to in tegrate into the bacterial chromosome as does the $F$ factor (Campbell, 1962). Evidence for such integration has 
been presented (Watanabe and Takano, 1962; Sugino and Hirota, 1962; Iyobe, Hashimoto and Mitsuhashi, 1969) and indirect mechanisms of integration are well established. Kondo and Mitsuhashi (1964) isolated a strain of Escherichia coli carrying a $\mathrm{P}_{1}$ prophage into which the gene for chloramphenicol acetyltransferase had been incorporated, replicating as part of the $\mathrm{P}_{1}$ plasmid (Kondo and Mitsuhashi, 1964). The resistance gene could be translocated either to an $F$ factor (Kondo and Mitsuhashi, 1966), which can integrate into the bacterial chromosome, or directly into the bacterial chromosome (Scott, 1970). Dubnau and Stocker (1964) used phage $\mathrm{P}_{22}$ to transduce $R$ factor markers in Salmonella typhimurium and found strains which had been lysogenised by $\mathrm{P}_{22}$ prophages from which genes had been deleted and replaced by genetic material from the $R$ factor. These prophages (most of which had lost the ability to produce phage particles) integrated at the normal attachment site of phage $P_{22}$. Similar transductants were produced when phage $\varepsilon^{15}$ was used to transduce $R$ factor genes in Salmonella anatum (Kameda, Harada, Suzuki and Mitsuhashi, 1965).

Thus, a single gene (the chloramphenicol acetyltransferase determinant) can exist as a chromosomal gene as part of the $R$ factor (capable of existing in cells of at least two orders of bacteria), as part of an $F$ factor (with a comparable host range), as part of a phage (that can lysogenise at least three bacterial genera (Bertani, 1951; Okada and Watanabe, 1968), integrated into a new bacterial chromosome (Iyobe et al., 1969)) or as part of a defective prophage integrated into a bacterial chromosome.

A "phylogenetic tree" based on $R$ factor enzymes would indicate anomolous relationships. This would be true of the proteins determined by other plasmids capable of transfer, e.g. $F$ and col factors. A similar argument applies to the proteins coded by those phages capable of lysogenising bacteria from several species, e.g. $\mathrm{P}_{1}$ and $\mathrm{P}_{2}$ (Bertani, 1951; Bertani, Torheim and Laurent, 1967). It could be argued that plasmid-borne genes were special cases and that their evolutionary history and potential were distinct from those of typical chromosomal genes.

There is evidence that this is not the case. For example, phage $\varepsilon^{\mathbf{1 5}}$ grown on a strain of Salmonella anatum carrying F'lac or F'ara (the lac or ara genes being derived from $E$. coli and so not perfectly homologous with the $S$. anatum chromosomal genes) produced transductants to lactose or arabinose utilisation many of which carry integrated defective prophages (Hedges, 1971). Thus an operon, normally a part of the chromosome of another genus of bacteria, can be transferred into the chromosome of $S$. anatum by phage $\varepsilon^{\mathbf{1 5}}$.

The genetical organisation of the bacterial chromosome, in which genes whose metabolic functions are related tend to form clusters, must favour this kind of transmission. Such a group of genes, for example the structural and regulatory genes of lactose metabolism, must inevitably evolve to form a coadapted set. This co-adaptation is particularly clear in the case of structural genes for proteins which are components of multi-enzyme complexes (Henning, Dennert, Hertel and Shipp, 1967). The clearest example may be the protein synthetic machinery; it seems that the bulk of ribosomal RNA, transfer RNA and ribosomal protein molecules are coded by the DNA of a short region of the Bacillus subtilis chromosome (Hartford and Sueoka, 1970). Similarly, in E. coli the genes coding for ribosomal proteins tend to fall into a short region of the genetic map. This cannot be regarded as constituting an operon since at least one non-ribosomal gene, $\arg R$, is 
located in this region (Taylor and Trotter, 1967). Thus there must be some reason other than common regulation of expression to explain why the genes should be clustered in this region.

\section{OPERONS AND SUPERGENES}

When the nonrandomness of the genes on the bacterial chromosome was first observed, several authors (e.g. Demerec, 1957; Clowes, 1960) suggested that the grouping of related genes was associated with the partial genetic transfer mechanisms so characteristic of bacteria. If only a small piece of genetic material could be transferred, those genes whose functions were metabolically co-ordinated should be transferable as a unit. This interpretation was superseded by the overwhelming success of the operon hypothesis (Jacob, Perrin, Sanchez and Monod, 1960) which demonstrated that certain groups of closely linked genes were transcribed on to single mRNA molecules, this transcription being regulated in various ways. This explanation is undoubtedly true but does not seem adequate to explain all the evidence. A good example is provided by the isoleucine-valine genes of $E$. coli. The structural genes for all the enzymes of this pathway form a tightly linked group but constitute three distinct operons (Ramakrishnan and Adelberg, 1965).

The arginine genes, though subject to a common repressor are scattered over the $E$. coli chromosome and although four of the structural genes are tightly linked they are not organised into a single operon (Baumberg, Bacon and Vogel, 1965). This is specially interesting because in a related genus, Proteus mirabilis, the linkage was similar, but one gene (unlinked to the group of four in E. coli) had been added to the cluster (Prozesky, 1968). Perhaps this difference shows two stages in the evolution of an operon. The genes involved in ribosome structure are another example (Hartford and Sueoka, 1970). It is hard to believe that the genes for these very diverse components could form a single operon in face of the evidence on the synthesis of rRNA (Adesnik and Levinthal, 1969).*

The arginine biosynthetic pathway demonstrates that quite separate genes may be subject to a common repression system. Each gene (or operon) has its own promoter so that levels of production of each enzyme may be individually determined (Jacoby and Gorini, 1969). Thus, explanations of the ordering of genes based upon regulatory mechanisms neither explain all observations nor provide a strong selective force to build up gene clusters.

If the operon hypothesis is insufficient to explain the clustering of related genes, the most plausible alternative is the view that there may be a selective advantage to such aggregation in organisms where partial genetic transfer is the rule. On this view, the bacterial chromosome contains many sets of "super genes" (Darlington and Mather, 1949). In bacteria many operons have evolved but rather few seem to have evolved in eukaryotes. It is difficult to understand how the genes of an operon have been so neatly assembled, since presumably only a very small proportion of chromosomal

* Recently several cases have been reported among the Enterobacteriaceae in which sets of metabolically related genes are closely linked on the bacterial chromosome but not organised into single operons. Specially noteworthy are the cases of the genes involved in biotin synthesis (Guha, Saturen and Szybalski, 1971) and histidine utilisation (Smith and Magasanik, 1971). Both of these gene clusters are closely linked to the galactose region and to the attachment sites of several lambdoid phages capable of special transduction. 
rearrangements fit a gene into an appropriate operon in such a way that it is regulated in advantageous fashion. It may be that in bacteria supergenes evolve by a crude reshuffling process bringing related genes into proximity and that operons evolve by subtler alterations within the already formed gene-clusters. Thus, operons are rare in eukaryotes because the selective forces to build up gene-clusters are absent and therefore the raw material from which operons can be built are not available.

\section{SPEGific EXAMPLES OF THE TRANSFER PROCESS}

Material from the chromosome of one bacterial species may be translocated (via an episome) into the chromosome of bacterium of a different genus. Does this transfer occur in the evolution of a chromosomal segment, or are these transfers just a laboratory curiosity? It is difficult to prove that a particular event occurred, but evidence of historical events may be deduced from an analysis of the present-day situation.

The lactose genes of $E$. coli have been the subject of intensive study. Many genera of the Enterobacteriaceae are unable to ferment lactose; so ability to metabolise this sugar may be of marginal significance and this ability may be a fairly recent evolutionary acquisition. If the lactose genes were part of a plasmid which has been inserted relatively recently, one might expect some evidence for disturbance of pre-existing linkage relationships. In fact, the lactose genes are inserted into a cluster of proline genes. The genetic sequence is pro $A$, proB, lac, proC (Schwartz, 1964). Whether insertion of the plasmid disrupted a pre-existent operon is obscure. On the one hand, the genes pro $A$ and $p r o B$ seem rather far apart to be considered as part of one operon (Taylor and Trotter, 1967)* but the proC gene (separated from proA and $B$ by the lac genes) seems to produce constitutively a completely unregulated enzyme (Baich and Pierson, 1965). If wild-type $E$. coli is given glutamic semialdehyde, this is converted uncontrolledly to proline and the excess excreted. This is just the sort of outcome one might expect of a gene dissociated from its control.

If an episome (carrying the lactose genes) had integrated into the $E$. coli chromosome, there might be some residual homology between the ends of the integrated structure (cf. Campbell, 1962). Recombination between these regions would eliminate the lactose genes completely. If maintenance of the genes was advantageous, strains might evolve in which the tendency to lose them was reduced. Deletion of one of the homology regions should have this' effect. Cook and Lederberg (1962) isolated $\mathrm{lac}^{-}$mutants from derivatives of $E$. coli $\mathrm{K}_{12}$. In some of these substrains a high proportion (about 40 per cent.) of all mutations were deletions of the entire lactose region. Some substrains, however, produced few such deletions. The genetic determination of this difference was not analysed.

Broda (1967) showed that on each side of the lactose operon there was a site at which the $F$ factor could integrate with notable efficiency. These two sites may be relics of the integrated episome. (Matney, Goldschmidt, Erwin and Scroggs (1964) report the existence of at least four other pairs of

* Condamine (1971) has presented evidence suggesting that the pro $A$ and proB genes are more closely linked than was previously supposed. He also reports the existence of revertible mutations which abolish the expression of both genes and suggests that they constitute an operon. 
closely linked $F$ attachment sites.) Berg and Curtiss (1967) studied an Hfr where the $F$ was integrated between proB and lac, pro $C$ with the former transferred as leading marker. They record two separate occasions on which the polarity of the Hfr was inverted so that proC became the first marker and pro $B$ one of the last to be transferred. The lactose operon was similarly inverted on the chromosome. It is difficult to explain these events without invoking a recombinational interaction between the integrated $F$ and the $F$-integration site between lac and proC.

If the lactose genes had evolved in a bacterial host other than $E$. coli, the presence of the gene for this galactoside transacetylase might be explained. This gene has been shown to form part of the lactose operon, but biochemical investigation has failed to show any metabolic function for the enzyme (Fox, Beckwith, Epstein and Signer, 1966). Perhaps in its original host the enzyme had a function. It is difficult to explain the origin of such an enzyme without making some such assumption.

If the genes for lactose metabolism were introduced into $E$. coli as part of a plasmid, one might expect to find evidence for comparable plasmids in contemporary populations of the Enterobacteriaceae. Such plasmids have been observed in Salmonella (Falkow and Baron, 1962), Proteus (Falkow, Wohlhieter, Citarella and Baron, 1964) and Klebsiella (Reeve and Braithwaite, 1970).

The compactness of the group of lactose genes is of some interest. This is not common in other metabolic pathways. For example, the repressor gene of the galactose operon is far removed from the structural genes (Saedler, Gullon, Fiethen and Starlinger, 1968) whilst in the arabinose system the permease gene is quite separate from the other genes (Novotny and Englesberg, 1966). There is no physiological reason why the repressor gene should be closely linked to the structural genes. If, however, all the lactose genes had been accommodated on a small plasmid which integrated into the relatively large bacterial chromosome it is easy to see that all the genes would be closely associated.

Thus, although no proof exists that the lactose genes of $E$. coli were acquired from some unknown source in the not too distant past, there is as much evidence in favour of this notion as one could reasonably expect.

\section{Evidence from Pseudomonas aeruginosa}

$P$. aeruginosa differs from the Enterobacteriaceae in the low degree of clustering of related genes (Fargie and Holloway, 1965). Recent studies have, however, revealed several examples of such clustering. Brammar, Clarke and Skinner (1967) showed that the structural gene for the aliphatic amidase was very closely linked to the regulatory gene; a situation apparently similar to that of the lactose of $E$. coli.

An instructive case is the $\beta$-ketoadipate pathway (Kemp and Hageman, 1968; Rosenberg and Hegeman, 1969). Some of the genes of this pathway were inducible by the same compounds. These were tightly linked and seem to constitute operons. "Surprisingly, some loci specifying enzymes not sharing a common inducer were also clustered. It may be that there is some overall loose clustering of the genes involved in aromatic acid catabolism in $P$. aeruginosa."

Why is the clustering of related genes less pronounced than in the Enterobacteriaceae? An explanation may be found in the behaviour of 
sex plasmids in $P$. aeruginosa. These tend to transfer the chromosome from a single site (Holloway, 1969). In E. coli, although sex factors with this sort of specificity are known (Kahn, 1968; Pearce and Meynell, 1968), other sex factors, e.g. $F$, transmit the chromosome with a variety of different gene orders (Matney, Goldschmidt, Erwin and Scroggs, 1964). In Pseudomonas matings a gene is thus always linked to all these genes that are transmitted before it, whilst in the Enterobacteriaceae there is no such regularity. It may be that the polarised genetic transfer of Pseudomonas has reduced the selective advantage conferred by clustering of co-adapted genes and thereby inhibited the assembly of gene clusters from which operons could be constructed.

\section{The evolution of girgular genomes}

The DNA molecules which constitute bacterial chromosomes, plasmids and some bacteriophage chromosomes are capable of forming circles. This could be advantageous in avoiding degradation by exonucleases (Fiers and Sinheimer, 1962) or could be explained as maximising linkage relationships (Stahl and Murray, 1966). Neither argument seems to offer a complete explanation. DNAs of many phages, including those which can exist and replicate as covalently closed circles, produce "free ended" structures during phases of replication and a phage, such as phage $\lambda$, has a linear linkage map (Jacob and Wollman, 1954) though its DNA can replicate in circular form (Carter, Shaw and Smith, 1969).

The simplest interpretation of circularity is that the genetic elements have evolved so as to exploit the evolutionary opportunities presented by genetical interactions. A linear DNA molecule can attach itself to the end of another DNA molecule but it can only integrate into the interior of such a molecule by replacing an homologous segment. This very limited potential for interaction may be contracted with the almost infinitely wide opportunities open to circular structures which can suffer recombination at any point producing a larger, circular, molecule containing the total information of both structures.

It seems that this type of integration-excision cycle has a very general role in the life-cycle of genetic elements in bacteria. Campbell (1969) suggested that in a bacterial cell different plasmids could interact through integration-excision cycles. A plasmid might exist as a single circle, as two (or more) smaller circular molecules or in equilibrium between the two states. A rather similar model of reversible association between an $R$ and an $F$ factor (autonomous or integrated) has been proposed by Anderson, Mayhow and Grindley (1969) and by Kameda, Harada, Suzuki and Mitsuhashi (1969). Also Cohen and Miller (1970a, $b$ ) showed that $R$ factors which exist as single DNA molecules in $E$. coli may break down into two dissimilar DNA circles in the cytoplasm of Proteus mirabilis. One of these molecules carries the genes responsible for the transferability whilst the other carries the drug resistance determinants. What seems to be a similar phenomenon was reported by Dubnau and Stocker (1967). They introduced $R$ factors and col factors independently into a strain of Salmonella typhimurium. Quite a high frequency of co-transduction of $R$ factor markers with colicinogenicity was observed. Apparently the two types of plasmid can associate after transfer into a common cytoplasm.

If one accepts the general interpretation of bacterial evolutionary patterns proposed one might expect an array of episomes and plasmids in 
various stages of evolution between non-defective prophages or autonomously transferring plasmids and normal chromosomal components. Many examples which may exemplify this evolutionary stage have been reported. For example, Ikeda, Inuzuka and Tomizawa (1970) have shown that $E$. coli 15 contains at least three different kinds of plasmids as well as at least two kinds of defective prophage.

\section{CONSEQUENGes FOR PHYLOGENETIG AND TAXONOMic STUdies}

If the course of bacterial evolution has involved the systematic exploitation of the mechanisms discussed earlier, then there are profound differences in the evolutionary courses of these organisms in contrast to those of eukaryotes. In the latter group it seems clear that in most cases we can assume that any present-day species has been derived by progressive evolutionary changes in a gene pool whose limits have been the normal interspecific barrier. Some exceptions, particular allopolyploidy, are well recognised but usually involve the fusion of complete genomes of the parental species. A few intriguing exceptions are known (for example, the transferable pyrimethamine resistance factor of Plasmodium (Ferone, O'Shea and Yoeli, 1970)), but on the present evidence these are extremely rare.

In bacteria the genetical material from a wide range of species may be reassembled to produce a progeny species for which no single parental species can be assigned. Perhaps it would be best to think of the bacteria as constituting one gene pool from which any "species" may draw genes as these are required. The most recent " demand" has been for genes conferring resistance to the various antibiotics and genes have been assembled presumably from chromosomes of bacteria naturally resistant to the antibiotics. On this view, whilst the "phylogenetic tree" is a reasonable representation of the evolution of eukaryotic species, a reticulate network would be required to represent the evolution of the genome of a bacterial species.

Bacterial taxonomy may also be influenced by the pattern of evolutionary change in these organisms. A taxonomy depicting well-defined species or groups of related species would be inherently unnatural whilst the real situation might be better represented by a picture of a continuous gene pool in which the "species" represent sets of genetic information which happen to be adaptive. My impression is that "computer taxonomy" is tending to produce a picture in conformity with the latter scheme (Sneath, 1964).

Somatic antigens have been found to be very variable in the Enterobacteriaceae. In Salmonella the chemical structures have been studied and used to construct a rather elaborate taxonomy. The chemical structures are less well known in other genera, but in $E$. coli the chemotypes (residues in the somatic antigen side chains) have been studied. Luderitz, Staub and Westphal (1966) have compared the chemotypes found in Salmonella with those known for strains of $E$. coli. There are extensive parallels. For example, 12 of the 16 Salmonella chemotypes have been found in $E$. coli. Thus, either there has been very extensive parallel evolution in the two genera or that the classification is unnatural (for example, that "E. coli" has evolved many times from many different "species" of Salmonella) or a chemotype evolved in one genus can be transferred to the other. The last seems most attractive, especially since all the genes for the specificity of the somatic antigen side-chain are located in a single cluster-the $r f b$ cluster - and so the 
genetic determinant of a new chemotype, which may depend on a number of genes can be transmitted as a unit.

\section{Summary}

1. The nature of the species may be different in prokaryotes and eukaryotes and this may be a determining feature in the way in which these groups of organisms respond to evolutionary challenges.

2 . In eukaryotes a species will normally depend on the genetic resources of its own gene pool. In bacteria, thanks to the transferability of plasmids and transducing phages, a bacterial line may be able to make use of genetical information from a very distantly related species.

3. If this is a frequent occurrence, then this type of genetical transfer must be reflected in any interpretation of the evolutionary patterns and taxonomic relationships of bacteria.

\section{REFERENCES}

ADESNIK, M., AND LEVINTHAL, c. 1969. Synthesis and maturation of ribosomal RNA in Escherichia coli. Fournal of Molecular Biology, 46, 281-303.

ANDERSON, E. S., MAYHEW, J. N., AND GRINDLEY, N. D. F. 1969. Transfer of a neomycinkanamycin resistance determinant by the $F$ factor of Escherichia coli $\mathrm{K}_{12}$. Nature, 222, 349-351.

BAICH, A., AND PIERSON, D. J. 1965. Control of proline syntheses in Escherichia coli. Biochimica et Biophysica Acta, 104, 397-404.

BARON, L. S., AND FALKow, s. 1961. Genetic transfer of episomes from Salmonella typhosa to Vibrio cholerae. Records of the Genetics Society of America, 30, 59.

BAUMBERG, S., BACON, D. F., AND VOGEL, H. J. 1965 . Individually repressible enzymes specified by clustered genes of arginine synthesis. Proceedings of the National Academy of Sciences Washington, 53, 1029-1032.

BERG, C. M., AND CURTISs, R. III. 1967. Transposition derivatives of an Hfr strain of Escherichia coli $\mathrm{K}_{12}$. Genetics, 56, 503-526.

Bertani, G. 1951. Studies on lysogenesis. I. The mode of phage liberation by lysogenic Escherichia coli. Journal of Bacteriology, 62, 293-300.

BERTANI, G., TORHEIM, B., AND LAURENT, T. 1967. Multiplication in Serratia of a bacteriophage originating from Escherichia coli: lysogenization and host controlled variation. Virology, $32,619-632$.

Brammer, W. J., Clarke, P. H., AND skinner, A. J. 1967. Biochemical and genetic studies with regulator mutants of the Pseudomonas aeruginosa 8602 amidase system. Fournal of General Microbiology, 47, 87-102.

BRODA, P. 1967. The formation of Hfr strains in Escherichia coli. Genetical Research, 9, 35-47. CAMPBELL, A. M. 1962. Episomes. Advances in Genetics, 11, 101-145.

CAMPBell, A. M. 1969. In the discussion following E. S. Anderson, " Ecology and epidemiology of transferable drug resistance ". CIBA Symposium on Bacterial Episomes and Plasmids, 102-119.

CARTER, B. J., SHAW, B. D., AND SMith, M. G. 1969. Two stages in the replication of bacteriophage DNA. Biochimica et Biophysica Acta, 195, 494-505.

CLOWES, R. C. 1960. Fine genetic structure as revealed by transduction. Symposium of the Society for General Microbiology, 10, 92-114.

COHEN, s. N., AND MILler, C. A. 1970a. Nonchromosomal antibiotic resistance in bacteria. II. Molecular nature of $\mathrm{R}$ factors isolated from Proteus mirabilis and Escherichia coli. Journal of Molecular Biology, 50, 671-687.

COHEN, s. N., AND MILleR, c. A. 1970b. Nonchromosomal antibiotic resistance in bacteria. III. Isolation of the discrete transfer unit of the $R$ factor R1. Proceedings of the national Academy of Sciences, 67, 510-516.

condamine, H. 1971. Mutants des voies biosynthèse et de dégradation de la proline chez E. coli $\mathrm{K}_{12}$. Annales de l'Insitut Pasteur, 120, 9-22.

COOK, A. M., AND LEDERBERG, J. 1962. Recombination studies of lactose non-fermenting mutants of Escherichia coli $\mathrm{K}_{12}$. Genetics, 47, 1335-1353.

DARLIngton, C. D., AND MATHER, K. 1949. The Elements of Genetics. 
DATTA, N. 1965. Infective inheritance of drug resistance in bacteria. Times Science Review, $57,12-13$.

DAYHOFF, M. о. 1969. Atlas of protein sequence and structure No. 4. National Biomedical Research Foundation.

DEMEREC, M. 1957. A comparative study of certain gene loci in Salmonella. Cold Spring Harbor on Quantitative Biology, 21, 113-121.

DEMEREC, M. 1964. Clustering of functionally related genes in Salmonella typhimurium. Proceedings of the National Academy of Sciences, Washington, 51, 1057-1060.

DUBNAU, E., AND stocker, B. A. D. 1964. Genetics of plasmids in Salmonella typhimurium. Nature, 204, 1112-113.

DUBNAU, E., AND STOCKER, B. A. D. 1967. Behaviour of three colicine factors and an $R$ (drug resistance) factor in Hfr crosses in Salmonella typhimurium. Genetical Research, 9, 283-297.

FALKOW, s., AND BARON, L. s. 1962. Episomic element in a strain of Salmonella typhosa. Journal of Bacteriology, 84, 581-589.

FAlKow, s., WOHLHIETER, J. A., CitARELla, R. V., AND BARON, L. s. 1964. Transfer of episomic elements to Proteus. II. Nature of $\mathrm{lac}^{+}$Proteus strains isolated from clinical specimens. Journal of Bacteriology, 88, 1598-1601.

FARGIE, B., AND HOLLOWAY, B. w. 1965. Absence of clustering of functionally related genes in Pseudomonas aeruginosa. Genetical Research, 6, 284-299.

FERONE, R., O'SHEA, M., AND YOELI, M. 1970. Altered dihydrofolate reductase associated with drug resistance transfer between rodent plasmodia. Science, 167, 1263-1264.

FIERS, W., AND SINSHEIMER, R. L. 1962. The structure of the DNA of bacteriophage $\varnothing \times 174$. I. The action of exopolynucleotidases. Fournal of Molecular Biology, 5, 408-419.

FOX, C. F., BECKWITH, J. R., EPSTEIN, W., AND SIGNER, E. R. 1966. Transposition of the lactose region of Escherichia coli. II. On the role of thiogalactoside transacetylase in lactose metabolism. Journal of Molecular Biology, 19, 576-579.

FULLBROOK, P. D., ELSON, s. w., AND SLOCOMBE, B. 1970 . $R$ factor mediated $\beta$-lactamase in Pseudomonas aeruginosa. Nature, 226, 1054-1056.

GUHA, A., SATUREN, Y., AND SZYBALSKI, w. 1971. Divergent orientation of transcription from the biotin locus of Escherichia coli. Fournal of Molecular Biology, 56, 53-62.

HARTFORD, N., AND SUEOKA, N. 1970. Chromosomal location of antibiotic resistance markers in Bacillus subtilis. Fournal of Molecular Biology, 51, 267-286.

Hedges, R. W. 1971. Transduction mechanisms of bacteriophage $\varepsilon^{\mathbf{1 5}}$. I. General properties of the system. Genetical Research, 18, 9-19.

HENNING, U., DENNERT, G., HERTEL, R., AND SHIPP, w. s. 1967. Translation of the structural genes of the E. coli pyruvate dehydrogenase complex. Cold Spring Harbor Sumposium on Quantitative Biology, 31, 227-234.

holloway, в. w. 1969. Genetics of Pseudomonas. Bacteriological Reviews, 33, 419-443.

IKEDA, H., INUZUKA, M., AND tomizAWA, J. 1970. $\mathbf{P}_{1}$-like plasmid in Escherichia coli $\mathrm{K}_{12}$. Fournal of Molecular Biology, 50, 457-470.

IYOBE, s., HASHIMOTO, H., AND MTTSUHASHI, s. 1969. Integration of chloramphenicol resistance gene of an $R$ factor on Escherichia coli chromosome. Fapanese Fournal of Microbiology, 13, 225-232.

JACOB, F., PERRIN, D., SANCHEZ, C., AND MONOD, J. 1960. L'opéron: groupe de gènes à expression coordonée par un opérateur. Comptes Rendus de l'Academie des Sciences, 250, 1727-1729.

JACOB, F., SCHAEFFER, P., AND WOllmaN, E. L. 1960 . Episomic elements in bacteria. Symposium of the Society for General Microbiology, 10, 67-91.

JACOB, F., AND wollman, E. L. 1954. Étude génétique d'un bactériophage tempéré d'Escherichia coli. I. Le système génétique du bactériophage $\lambda$. Annales de l'Institut Pasteur, 87, 653-673.

JACOBY, G. A., AND GORINI, L. 1969. A unitary account of the repression mechanism of arginine biosynthesis in Escherichia coli. I. The genetic evidence. Fournal of Molecular Biology, 39, 73-87.

KAHN, P. L. 1968. Isolation of high frequency recombining strains from Escherichia coli containing the $\mathrm{V}$ colicinogenic factor. Fournal of Bacteriology, 96, 205-214.

KAMEDA, M., HARADA, K., SUZUKI, M., AND MrTSUHASHI, s. 1965. Drug resistance of enterobacteria. V. High frequency of transduction of $R$ factors with bacteriophage epsilon. Fournal of Bacteriology, 90, 1174-1181.

KAMEDA, M., HARADA, K., SUZUKI, M., AND MTTSUHASHI, s. 1969. Formation of transferable drug resistance by recombination between resistance determinants and transfer factors. Japanese Journal of Microbiology, 13, 255-262. 
KEMP, M. B., AND HEGEMAN, G. D. 1968. Genetic control of the $\beta$-ketoadipate pathway in Pseudomonas aeruginosa. Journal of Bacteriology, 96, 1488-1499.

Kondo, E., AND missuhashi, s. 1964. Drug resistance of enteric bacteria. IV. Active transducing bacteriophage $\mathrm{P}_{1} \mathrm{Cm}$ produced by the combination of the $R$ factor with bacteriophage $\mathrm{P}_{1}$. Fournal of Bacteriology, 88, 1266-1276.

KONDO, E., AND MITSUHASHI, s. 1966. Drug resistance of enteric bacteria. VI. Introduction of bacteriophage $\mathrm{P}_{1} \mathrm{Cm}$ into Salmonella typhi and formation of $\mathrm{P}_{1} d C m$ and $F C m$ elements. Fournal of Bacteriology, 91, 1787-1794.

LÜDERITZ, O., STAUB, A. M., AND WESTPHAL, o. 1966. Immunochemistry of $\mathrm{O} \& \mathrm{R}$ antigens of Salmonella and related enterobacteriaceae. Bacteriological Reviews, 30, 192-255.

MCLAUGHLIN, P. J., AND DAYHOFF, M. O. 1970. Eukaryotes versus prokaryotes: an estimate of evolutionary distance. Science, 168, 1469-1471.

MANDEL, M. 1969. New approaches to bacterial taxonomy: perspective and prospects. Annual Review of Microbiology, 23, 239-274.

martin, G., AND JACOB, F. 1962. Transfert de l'épisome sexuel d'Escherichia coli à Pasteurella pestis. Comptes rendus de l'Academie des Sciences, 254, 3589-3590.

MATNEY, T. S., GOLDSCHMIdT, E. P., ERWIN, N. S., AND SCROgGS, R. A. 1964. A preliminary map of genomic sites for $F$-attachment in Escherichia coli $\mathrm{K}_{12}$. Biochemical ED Biophysical Research Communications, 17, 278-281.

NAKAYA, R., NAKAMURA, A., AND mUROTA, Y. 1960. Resistance transfer agents in Shigella. Biochemical and Biophysical Research Communications, 3, 654-659.

NOvotNy, C. P., AND ENGLEsBerg, E. 1966. The 1-arabinose permease system in Escherichia coli B/r. Biochimica et Biophysica Acta, 117, 217-230.

OKadA, M., AND Watanabe, T. 1968. Transduction with phage $\mathrm{P}_{\mathrm{I}}$ in Salmonella typhimurium. Nature, 218, 185-187.

PEARCE, L, E., ANO MEYNELl, E. 1968. Specific chromosomal affinity of a resistance factor. Journal of General Microbiology, 50, 159-172.

PROzesky, o. w. 1968. Transductional analysis of arginineless mutants in Proteus mirabilis. Journal of General Microbiology, 54, 127-143.

RAMAKRISHNAN, T., AND ADELBERG, E. A. 1965. Regulatory mechanisms in the biosynthesis of isoleucine and valine. III. Map order of the structural genes and operator genes. Journal of Bacteriology, 89, 661-664.

REEVE, E. G. R., AND BRAITHWAITE, J. A. 1970. $F_{k} l a c$, an episome with unusual properties found in a wild strain of Klebsiella species. Nature, 228, 162-164.

ROSENBERG, s. L., AND HEGEMAN, G. D. 1969. Clustering of functionally related genes in Pseudomonas aeruginosa. Fournal of Bacteriology, 99, 353-355.

ROWND, R., NAKAYA, R., AND NAKAMURA, A. 1966. Molecular nature of the drug resistance factors of the enterobacteriaceae. Fournal of Molecular Biology, 17, 376-393.

SAEDler, H., GUllon, A., FIEThen, L., AND STARLinger, P. 1968. Negative control of the galactose operon in E. coli. Molecular E General Genetics, 102, 79-88.

SCHWARTz, N. M. 1964. Suppression of a $\mathrm{lac}^{\circ}$ mutation in Escherichia coli. Fournal of Bacteriology, 88, 996-1001.

scott, J. R. 1970. A defective $\mathbf{P}_{1}$ prophage with a chromosomal location. Virology, 40, 144-151.

SHAw, w. V. 1967. Enzymic acetylation of chloramphenicol by extracts of $R$ factorresistant Escherichia coli. Journal of Biological Chemistry, 242, 687-693.

SMITH, G. R., AND MAGASANIK, B. 1971. Nature and self-regulated synthesis of the repressor of the hut operons in Salmonella typhimurium. Proceedings of the National Academy of Sciences, Washington, 68, 1493-1497.

SNEATH, P. H. A. 1964. New approaches to bacterial taxonomy: use of computers. Annual Review of Microbiology, 18, 335-346.

STAHL, F. W., AND MURRAY, N. E. 1966. The evolution of gene clusters and genetic circularity in microorganisms. Genetics, 53, 569-576.

SUGINO, Y., AND HIROTA, Y. 1962. Conjugal fertility associated with resistance factor in Escherichia coli. Fournal of Bacteriology, 84, 902-910.

SYKES, R. B., AND RICHMOND, M. H. (1970). Intergeneric transfer of a $\beta$-lactamase gene between $P$. aeruginosa and $E$. coli. Nature, 226, 952-954.

TAYLOR, A. L., AND TROTTER, C. D. 1967. Revised linkage map of Escherichia coli. Bacteriological Reviews, 31, 332-353.

WATANABE, T., And takano, T. 1962. Quoted in Watanabe, T. (1963), Infective heredity of multiple drug resistance in bacteria. Bacteriological Reviews, 27, 87-115. 